\title{
Backcrossing of a capercaillie $\times$ black grouse hybrid male in the wild revealed with molecular markers
}

\author{
Oddmund Kleven $^{1}$ (D) $\cdot$ Henrik Brøseth ${ }^{1}$ (D) $\cdot$ Kyrre Jonassen $^{2} \cdot$ Hans Christian Pedersen $^{1}$
}

Received: 23 October 2019 / Revised: 10 March 2020 / Accepted: 20 March 2020 /Published online: 31 March 2020

(C) The Author(s) 2020

\begin{abstract}
The black grouse Lyrurus tetrix and the capercaillie Tetrao urogallus are known to produce hybrids in wild populations. In general, these hybrids are regarded as infertile; however, conclusive evidence that F1-hybrids are infertile and unable to backcross in the wild are lacking. Using a molecular approach, we examined the ancestry of a bird assumed to be a male hybrid based on phenotypic characters. The specimen was legally shot during the hunting season in northern Norway in an area where the black grouse is common and the capercaillie is relatively rare. Analysis of the maternally inherited mitochondrial DNA revealed that the mother of the specimen was of capercaillie origin, while a diagnostic sex-chromosome $(Z)$ linked microsatellite marker showed that the father had a black grouse allele. Diagnostic autosomal microsatellite markers revealed that the specimen was a backcross and not a first-generation hybrid. As galliform birds follow Haldane's rule, i.e., that hybrid sterility is common in the heterogametic sex (female in birds), the hybrid parent of the backcross was, thus, likely a male. Our findings provide molecular evidence that capercaillie $\times$ black grouse F1-hybrid males can be fertile and successfully mate and backcross in a wild population.
\end{abstract}

Keywords Hybridization $\cdot$ MtDNA $\cdot$ Microsatellites $\cdot$ Lyrurus tetrix $\cdot$ Tetrao urogallus

\section{Introduction}

Hybridization between some grouse species is rather common (Johnsgard 1983; McCarthy 2006), especially the combination of the black grouse Lyrurus tetrix and the capercaillie Tetrao urogallus which has been well known in Scandinavia as early as 1744 (Johnsgard 1983). Male hybrids between a male black grouse and a female capercaillie are the most common hybrids and they have even been given a specific name, "rakkelhane" in Norwegian. These male hybrids are observed most often on black grouse leks during spring, where they dominate and

Electronic supplementary material The online version of this article (https://doi.org/10.1007/s10344-020-01377-y) contains supplementary material, which is available to authorized users.

Oddmund Kleven

oddmund.kleven@nina.no

1 Norwegian Institute for Nature Research (NINA), NO-7485 Trondheim, Norway

2 Løpsmarka 61, NO-8015, Bodø, Norway sometimes kill black grouse males (Andersen 2015), and are reproductively active (Porkert et al. 1997). Black grouse females do not solicit copulations with hybrid males, however, female capercaillie do so (Porkert et al. 1997; Flor 2009). In captivity, it has been shown that first-generation (F1) hybrid males have viable spermatozoa despite reduced semen quality (Ciereszko et al. 2009), and that they are indeed fertile and able to backcross with capercaillie females (Johnsgard 1983; Höglund and Porkert 1989). However, female F1-hybrids were sterile (Höglund and Porkert 1989). In general, hybrid sterility is common in the heterogametic sex (Haldane 1922), and it has been shown that galliform birds follow Haldane's rule (Arrieta et al. 2013). Both skin material and description of lekking behavior of wild birds exist for probable F2- and F3-hybrid birds (Porkert et al. 1996; Porkert et al. 1997). However, conclusive evidence for such backcrossing in wild populations is currently lacking.

In this study, we used species-specific genetic markers to analyse a grouse specimen assumed to be a capercaillie $\times$ black grouse hybrid male based on phenotypic characters. The main aim was to test if the specimen was a hybrid and, if so, identify the maternal and paternal species origin. 


\section{Materials and methods}

On 2 November 2013 a grouse, assumed to be a male capercaillie, was legally shot during the hunting season in Bodø municipality in northern Norway $\left(67^{\circ} \mathrm{N}, 14^{\circ} \mathrm{E}\right)$. The bird had several phenotypical characteristics of both the black grouse and the capercaillie. The bird was sent to the NTNU University Museum in Trondheim, where the specimen was mounted and are kept, and a tissue sample was obtained for DNA analysis. Additionally, body mass, total wing length (flattened and stretched), and length of central tail feathers were measured. As reference material for the molecular analyses, we used DNA from 15 capercaillie and 15 black grouse individuals from central Norway, collected as part of a previous project on power-line induced mortality (Bevanger et al. 2014).
DNA analysis was carried out at the DNA laboratory at the Norwegian Institute for Nature Research in Trondheim. Genomic DNA was extracted with the DNeasy blood and tissue kit (Qiagen) following the manufacturer's protocol. To determine the maternal origin of the specimen, we sequenced a standard barcoding region of the cytochrome oxidase I (COI) gene (Hebert et al. 2004), which is located on the mitochondria and, thus, maternally inherited. DNA was amplified and sequenced using the primers BirdF1 and BirdR2 (Hebert et al. 2004; Kerr et al. 2007). To determine the paternal origin of the specimen, we analysed five autosomal loci and one sex-linked (Z-chromosome) locus (Table 1) that all had been shown to differ in fragment sizes between the capercaillie and the black grouse (Jacob et al. 2010; O. Kleven unpublished data).
Table 1 Microsatellite genotypes of the hybrid specimen and reference samples from the black grouse Lyrurus tetrix and capercaillie Tetrao urogallus

\begin{tabular}{|c|c|c|c|c|c|c|c|}
\hline Species & Sex & $\mathrm{BG} 15^{1}$ & $\mathrm{BG} 18^{1}$ & Clock $^{2}$ & $\mathrm{sTuD}^{3}$ & sTuT2 $^{3}$ & $Z-054^{4^{*}}$ \\
\hline Hybrid specimen & Male & $140 / 140$ & $160 / 200$ & $271 / 276$ & $139 / 147$ & $160 / 164$ & $244 / 254$ \\
\hline Black grouse & Female & $190 / 206$ & $160 / 164$ & $271 / 271$ & $91 / 91$ & $118 / 118$ & 254 \\
\hline Black grouse & Female & 190/190 & $156 / 160$ & $271 / 271$ & 91/91 & $118 / 118$ & 254 \\
\hline Black grouse & Female & 198/198 & $160 / 168$ & $271 / 271$ & $91 / 91$ & $118 / 118$ & 250 \\
\hline Black grouse & Female & 198/198 & $168 / 172$ & $271 / 271$ & 91/91 & $118 / 118$ & 250 \\
\hline Black grouse & Female & $186 / 190$ & $156 / 168$ & $271 / 271$ & $91 / 91$ & $118 / 118$ & 254 \\
\hline Black grouse & Female & $178 / 186$ & $168 / 168$ & $271 / 271$ & 91/91 & $118 / 118$ & 250 \\
\hline Black grouse & Female & 190/194 & $168 / 172$ & $271 / 271$ & 91/91 & $118 / 118$ & 254 \\
\hline Black grouse & Female & $186 / 190$ & $160 / 160$ & $271 / 271$ & 91/91 & $118 / 118$ & 254 \\
\hline Black grouse & Female & $186 / 190$ & $160 / 168$ & $271 / 271$ & 91/91 & $118 / 118$ & 254 \\
\hline Black grouse & Male & $190 / 190$ & $164 / 168$ & $271 / 271$ & $91 / 91$ & $118 / 118$ & $250 / 254$ \\
\hline Black grouse & Male & $186 / 206$ & $156 / 160$ & $271 / 271$ & $91 / 91$ & $118 / 118$ & $250 / 250$ \\
\hline Black grouse & Male & $182 / 190$ & $156 / 160$ & $271 / 271$ & $91 / 91$ & $118 / 118$ & $254 / 258$ \\
\hline Black grouse & Male & $186 / 194$ & $160 / 160$ & $271 / 271$ & $91 / 91$ & $118 / 118$ & $254 / 254$ \\
\hline Black grouse & Male & $182 / 194$ & $156 / 160$ & $271 / 271$ & $91 / 91$ & $118 / 118$ & $250 / 254$ \\
\hline Black grouse & Male & $186 / 190$ & $156 / 160$ & $271 / 271$ & $91 / 91$ & $118 / 118$ & $254 / 254$ \\
\hline Capercaillie & Female & $136 / 144$ & $192 / 208$ & $276 / 276$ & $129 / 137$ & $152 / 160$ & 244 \\
\hline Capercaillie & Female & $136 / 144$ & $196 / 200$ & $276 / 276$ & $135 / 143$ & $144 / 152$ & 244 \\
\hline Capercaillie & Female & $136 / 144$ & $192 / 196$ & $276 / 276$ & $137 / 141$ & $144 / 152$ & 246 \\
\hline Capercaillie & Female & $136 / 136$ & $200 / 204$ & $276 / 276$ & $135 / 143$ & $144 / 168$ & 244 \\
\hline Capercaillie & Female & $136 / 140$ & $196 / 200$ & $276 / 276$ & $135 / 141$ & $160 / 164$ & 244 \\
\hline Capercaillie & Female & $136 / 140$ & $196 / 200$ & $276 / 276$ & $143 / 153$ & $144 / 152$ & 244 \\
\hline Capercaillie & Female & $136 / 136$ & $192 / 200$ & $276 / 276$ & $145 / 153$ & $152 / 152$ & 244 \\
\hline Capercaillie & Male & $140 / 140$ & $188 / 204$ & $276 / 276$ & $135 / 145$ & $144 / 160$ & $244 / 244$ \\
\hline Capercaillie & Male & $136 / 140$ & $200 / 200$ & $276 / 276$ & $137 / 143$ & $152 / 156$ & $244 / 244$ \\
\hline Capercaillie & Male & $136 / 136$ & $196 / 200$ & $276 / 276$ & $133 / 135$ & $144 / 156$ & $244 / 246$ \\
\hline Capercaillie & Male & $136 / 136$ & 192/196 & $276 / 276$ & $141 / 143$ & $144 / 144$ & $244 / 244$ \\
\hline Capercaillie & Male & $136 / 136$ & $200 / 208$ & $276 / 276$ & $135 / 137$ & $144 / 156$ & $244 / 244$ \\
\hline Capercaillie & Male & $132 / 144$ & $200 / 204$ & $276 / 276$ & $135 / 143$ & $152 / 164$ & $244 / 244$ \\
\hline Capercaillie & Male & $132 / 140$ & $196 / 204$ & $276 / 276$ & $137 / 143$ & $144 / 156$ & $244 / 244$ \\
\hline Capercaillie & Male & $140 / 140$ & $192 / 204$ & $276 / 276$ & $143 / 145$ & $152 / 156$ & $244 / 244$ \\
\hline
\end{tabular}

Primers from ${ }^{1}$ Piertney and Höglund (2001); ${ }^{2}$ Johnsen et al. (2007); ${ }^{3}$ Jacob et al. (2010); ${ }^{4}$ Dawson et al. (2015). *In birds, females are the heterogametic sex (ZW) and thus carry only one copy of the $\mathrm{Z}$ chromosome For the hybrid specimen, alleles in bold indicate black grouse alleles and italics indicate capercaillie alleles 

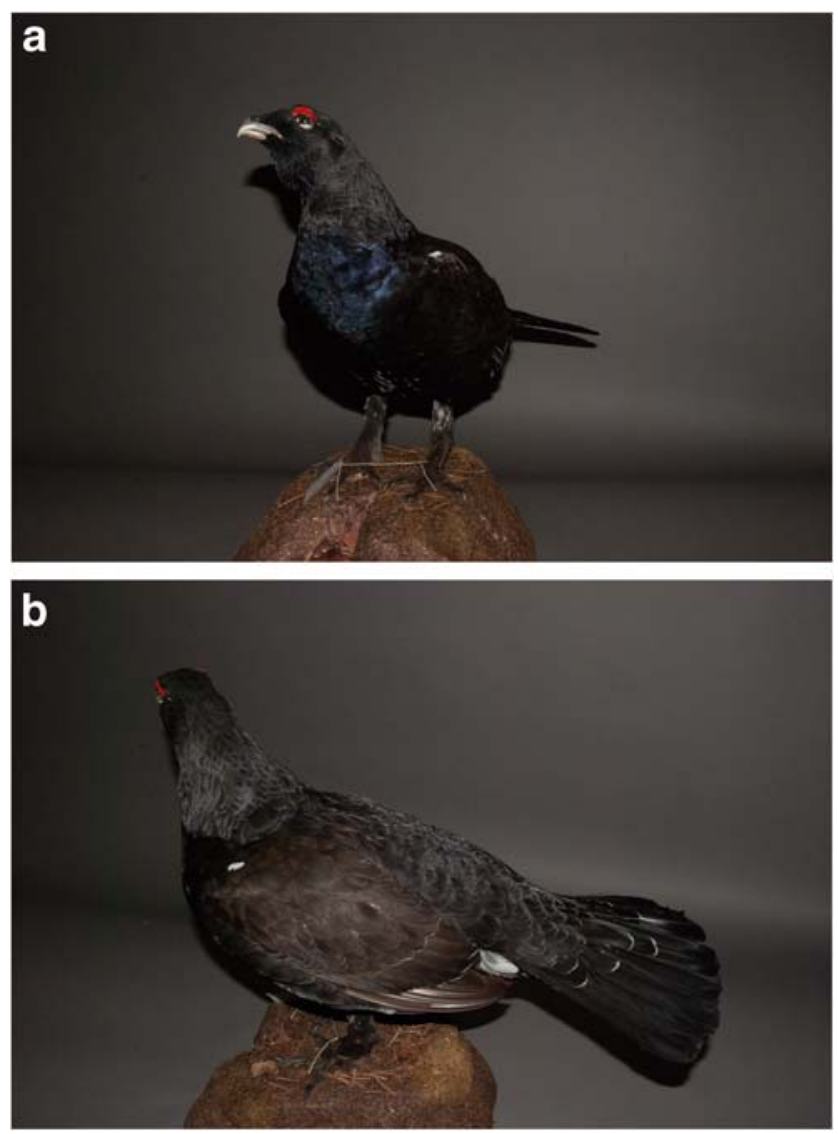

Fig. 1 Photos taken 5 February 2020 showing the investigated bird. The specimen was mounted by taxidermist Per Gätzschmann and is stored at the NTNU University Museum in Trondheim, Norway

To determine the maternal origin of the investigated specimen, the amplified mitochondrial sequence was compared with reference sequences in the Barcode of Life Database (Ratnasingham and Hebert 2007).

The 30 reference samples (autosomal microsatellite genotypes) from the black grouse and the capercaillie were used to generate 100 simulated genotypes for each of five classes, i.e., pure black grouse, pure capercaillie, first generation hybrids (F1), backcross (male F1 x female capercaillie), and second generation hybrids (F2) using HybridLab (Nielsen et al. 2006). The simulated genotypes and the genotype of the investigated specimen was then analysed using NewHybrids (Anderson and Thompson 2002) to calculate the probability that the investigated specimen belong to one of the five genotype frequency classes. NewHybrids was run with an initial burn-in of $1 \times 10^{-5}$ iterations followed by $1 \times 10^{-6}$ Monte Carlo Markov Chain generations.

\section{Results and discussion}

The investigated specimen had several phenotypic characteristics of a capercaillie, like horn-white beak, brownish wings, greyish-black back, and a rounded tail with straight outer tail feathers. However, the breast feathers had a metallic blue/ violet colour more similar to black grouse, not greenish as in capercaillie (see photos in Fig. 1). The bird weighed 3403 g, total wing length was $351 \mathrm{~mm}$ and length of central tail feathers was $230 \mathrm{~mm}$. Biometric data from the literature showed that male capercaillie weigh $3720-4800$ g, wing length range from 383 to $400 \mathrm{~mm}$ and central tail feathers range from 291 to $322 \mathrm{~mm}$, while male black grouse weigh 1050-1750 g, wing length range from 247 to $266 \mathrm{~mm}$ and central tail feathers range from 98 to $108 \mathrm{~mm}$ (Cramp 1980). Both the phenotypic characteristics and the biometric measurements of the focal bird, thus, indicated that it was a hybrid.

A 440-base-pair fragment was amplified from the maternally inherited mitochondrial COI region of the investigated specimen (GenBank accession number: MT037872). An identification search in the BOLD data base revealed that the sequence matched (99.8\% similarity) to the capercaillie (Online Resource 1). The mother of the investigated specimen was, thus, of capercaillie origin.

At the Z-linked microsatellite locus (Z-054), the investigated specimen was heterozygous (Table 1). Thus, confirming the sex as male, because males are the homogametic (ZZ) sex and females the heterogametic (ZW) sex in birds. One of the two alleles (244 bp) was identical to an allele found in the capercaillie only, while the other allele ( $254 \mathrm{bp}$ ) was identical to an allele found in the black grouse only (Table 1). The two different and species diagnostic alleles on the Z-linked locus showed that the investigated specimen was a hybrid. As the mtDNA revealed that the mother was a capercaillie, the Z-linked locus indicated that the father was of black grouse origin.

An examination of the microsatellite genotype of the investigated specimen showed that of ten autosomal alleles, eight were identical to alleles found in the capercaillie only, while two were identical to alleles found in the black grouse only (Table 1). As a F1-hybrid will share half of the genome with each of the two parental species, the father (as female hybrids are sterile; Höglund and Porkert 1989) of the investigated specimen, thus, also had to be a hybrid. This was further supported by the Bayesian model-based clustering analysis in NewHybrids (Anderson and Thompson 2002), which revealed that the investigated specimen most likely was a backcross (posterior probability 0.81 ) of a male F1-hybrid and a female capercaillie. As some simulated F2 genotypes had similar posterior probability values of being a backcross (Online Resource 2), we cannot exclude the possibility that the investigated specimen was a F2-hybrid. However, given the rarity of F1-hybrids, this seem less likely. A schematic illustration of the most likely pedigree of the investigated specimen is shown in Online Resource 3.

In general, it has been shown that hybridization occurs more frequently when one of the two hybridizing species is rare (Randler 2002). In the area where the investigated hybrid 
specimen was shot, the population size of the capercaillie was very low, while the black grouse were abundant (KJ pers. obs.). A female capercaillie in this area would, thus, more likely encounter a male black grouse than a male capercaillie, and produce a F1-hybrid. Behavioural observations in the wild have revealed that capercaillie $\times$ black grouse F1hybrid males attend and display on both black grouse and capercaillie leks (Porkert et al. 1997). While female capercaillie solicit copulations with hybrid males, black grouse females do not (Porkert et al. 1997). Backcrossing will, therefore, most likely involve hybrid males and capercaillie females.

In conclusion, we have in this study molecularly determined the parental origin of a wild capercaillie $\times$ black grouse hybrid specimen. Our findings provide molecular evidence that capercaillie $\times$ black grouse hybrid males can be fertile and successfully mate to produce backcrosses in wild populations under natural conditions.

Acknowledgments We are grateful to Per Gätzschmann at the NTNU University Museum for biometric data and the tissue sample of the hybrid specimen. We thank Massimo Scandura and two anonymous reviewers for constructive comments on a previous version of this manuscript. The hybrid specimen was legally shot during the hunting season in adherence with the regulations issued by the Norwegian Environmental Agency.

Funding information Open Access funding provided by Norwegian institute for nature research. Financial support was received from the Norwegian Institute for Nature Research (NINA).

Open Access This article is licensed under a Creative Commons Attribution 4.0 International License, which permits use, sharing, adaptation, distribution and reproduction in any medium or format, as long as you give appropriate credit to the original author(s) and the source, provide a link to the Creative Commons licence, and indicate if changes were made. The images or other third party material in this article are included in the article's Creative Commons licence, unless indicated otherwise in a credit line to the material. If material is not included in the article's Creative Commons licence and your intended use is not permitted by statutory regulation or exceeds the permitted use, you will need to obtain permission directly from the copyright holder. To view a copy of this licence, visit http://creativecommons.org/licenses/by/4.0/.

\section{References}

Andersen L (2015) The crazy Rackelhahn - Rakkelhanen (English subtitles). YouTube. https://www.youtube.com/watch?v= HqFF1QsWGRY. Accessed 10. February 2020

Anderson EC, Thompson EA (2002) A model-based method for identifying species hybrids using multilocus genetic data. Genetics 160(3):1217-1229

Arrieta RS, Lijtmaer DA, Tubaro PL (2013) Evolution of postzygotic reproductive isolation in galliform birds: analysis of first and second hybrid generations and backcrosses. Biol J Linnean Soc 110 (3): 528-542. https://doi.org/10.1111/bij.12153

Bevanger K, Bartzke G, Brøseth H, Dahl EL, Gjershaug JO, Hanssen F, Jacobsen K-O, Kleven O, Kvaløy P, May R, Meås R, Nygård T, Refsnæs S, Stokke S, Thomassen J (2014) Optimal design and routing of power lines; ecological, technical and economic perspectives (OPTIPOL). Final Report, findings 2009-2014. NINA report 1014. Norwegian Institute for Nature Research, Trondheim

Ciereszko A, Kowalczyk A, Lukaszewicz E, Krzywinski A, Kobus A, Dietrich GJ (2009) Sperm characteristics of male hybrid from a cross between male black grouse Tetrao tetrix and female capercaillie T. urogallus. Ornis Fenn 86(4):149-152

Cramp S (ed) (1980) Handbook of the birds of Europe, the Middle East and North Africa: the birds of the western Palearctic, vol II: Hawks to bustards. Oxford University Press, New York

Dawson D, Bird S, Horsburgh G, Ball A (2015) Autosomal and Z-linked microsatellite markers enhanced for cross-species utility and assessed in a range of birds, including species of conservation concern. Conserv Genet Resour 7(4):881-886. https://doi.org/10.1007/ s12686-015-0495-6

Flor A (2009) Hybrid mating a capercaillie female on a black grouse lek. YouTube. https://www.youtube.com/watch?v=We9ROXhtJsY. Accessed 10. February 2020

Haldane J (1922) Sex ratio and unisexual sterility in hybrid animals. J Genet 12:101-109

Hebert PDN, Stoeckle MY, Zemlak TS, Francis CM (2004) Identification of birds through DNA barcodes. PLoS Biol 2(10):e312. https://doi. org/10.1371/journal.pbio.0020312

Höglund NH, Porkert J (1989) Experimentelle kreuzungen zwischen auer- und birkhuhn (Tetrao urogallus et Tetrao tetrix). Z Jagdwiss 35:221-234

Jacob G, Debrunner R, Gugerli F, Schmid B, Bollmann K (2010) Field surveys of capercaillie (Tetrao urogallus) in the Swiss Alps underestimated local abundance of the species as revealed by genetic analyses of non-invasive samples. Conserv Genet 11(1):33-44. https://doi.org/10.1007/s10592-008-9794-8

Johnsen A, Fidler AE, Kuhn S, Carter KL, Hoffmann A, Barr IR, Biard C, Charmantier A, Eens M, Korsten P, Siitari H, Tomiuk J, Kempenaers B (2007) Avian clock gene polymorphism: evidence for a latitudinal cline in allele frequencies. Mol Ecol 16(22):4867-4880. https://doi. org/10.1111/j.1365-294X.2007.03552.x

Johnsgard PA (1983) The grouse of the world. Croom Helm, London

Kerr KCR, Stoeckle MY, Dove CJ, Weigt LA, Francis CM, Hebert PDN (2007) Comprehensive DNA barcode coverage of north American birds. Mol Ecol Notes 7(4):535-543. https://doi.org/10.1111/j.14718286.2006.01670.x

McCarthy EM (2006) Handbook of avian hybrids of the world. Oxford University Press, New York

Nielsen EE, Bach LA, Kotlicki P (2006) HYBRIDLAB (version 1.0): a program for generating simulated hybrids from population samples. Mol Ecol Notes 6(4):971-973. https://doi.org/10.1111/j.1471-8286. 2006.01433.x

Piertney SB, Höglund J (2001) Polymorphic microsatellite DNA markers in black grouse (Tetrao tetrix). Mol Ecol Notes 1(4):303-304. https://doi.org/10.1046/j.1471-8278.2001.00118.x

Porkert J, Lifjeld JT, Tornberg R (1996) Backcrossings of Tetrao hybrids, T. tetrix male $\mathrm{x} T$. urogallus female, with their parent species: a description of female offspring based on museum skins. Aquilo Ser Zool 29:33-41

Porkert J, Solheim R, Flor A (1997) Behaviour of hybrid male Tetrao tetrix males $\hat{\jmath} \times T$. urogallus females + on black grouse leks. Wildl Biol 3(3\&4):169-176

Randler C (2002) Avian hybridization, mixed pairing and female choice. Anim Behav 63:103-119

Ratnasingham S, Hebert PDN (2007) BOLD: the barcode of life data system (www.barcodinglife.org). Mol Ecol Notes 7(3):355-364. https://doi.org/10.1111/j.1471-8286.2007.01678.x

Publisher's note Springer Nature remains neutral with regard to jurisdictional claims in published maps and institutional affiliations. 